\title{
The Roles of Emotional Intelligence, Neuroticism, and Academic Stress on the Relationship Between Psychological Distress and Burnout in Medical Students
}

Muhamad Saiful Bahri Yusoff ( $\sim$ msaiful_bahri@usm.my )

Universiti Sains Malaysia

Siti Nurma Hanim Hadie

Universiti Sains Malaysia

Mohd Azhar Mohd Yasin

Universiti Sains Malaysia

\section{Research Article}

Keywords: Burnout, Psychological Distress, Emotional Intelligence, Neuroticism, Academic Stress

Posted Date: January 29th, 2021

DOl: https://doi.org/10.21203/rs.3.rs-144736/v1

License: () (7) This work is licensed under a Creative Commons Attribution 4.0 International License.

Read Full License 


\section{Abstract}

Background: Stress and burnout commonly threaten the mental health of medical students in Malaysia and elsewhere. This study aimed to explore the interrelations of psychological distress, emotional intelligence, personality traits, academic stress, and burnout among medical students. A cross-sectional study was conducted with 241 medical students. Validated questionnaires were administered to measure burnout, psychological distress, emotional intelligence, personality traits, and academic stress, respectively. A structural equation modelling analysis was performed by AMOS.

Results: The results suggested a structural model with good fit indices, in which psychological distress and academic stress were noted to have direct and indirect effects on burnout. The burnout levels significantly increased with the rise of psychological distress ( $p$-value $<0.01)$ and academic stress ( $p$ value $<0.01$ ). Neuroticism was only found to have significant indirect effects on burnout, whereby burnout increased when neuroticism increased ( $p$-value $<0.010)$. Emotional intelligence had a significant direct effect on lowering burnout with the incremental increase of emotional intelligence ( $p$-value $<0.05$ ), but it was significantly reduced by psychological distress and neuroticism ( $p$-value $<0.001$ ).

Conclusion: This study showed significant effects that psychological distress, emotional intelligence, academic stress, and neuroticism have on burnout. Academic stress and neuroticism significantly increased psychological distress, leading to an increased burnout level, while emotional intelligence had a significant direct effect on reducing burnout; however, this relationship was compromised by psychological distress and neuroticism, leading to increased burnout. Several practical recommendations for medical educators, medical students, and medical schools are discussed.

\section{Introduction}

Psychological distress is an unpleasant emotional state experienced by individuals in response to demands that cause mental disturbances (1). Psychological distress is a multi-facet construct that correlate with poor mental health and function $(2,3)$. Literature has shown psychological distress is more prevalent in medical students than the public $(4,5)$. However, before the medical training start, medical students have shown a similar level of psychological health as compared to the public (5-8). In comparison to undergraduate students across 15 courses, the students enrolled in medicine and health science courses showed the highest psychological distress scores (9). These facts suggest medical training is challenging and demanding for young medical students (10). Given its prevalence and the serious nature of the consequences, understanding the underlying factors contributing to psychological distress is imperative for necessary intervention.

Mental health implies a state of wellbeing enabling individuals to realise their abilities, cope with the normal stresses of life, work productively, and contribute to their communities (11). Unfortunately, some components of training have unintended and detrimental impacts on students' mental health. A high proportion of students experience high academic-related stress (12-15). The negative factors 
contributing to psychological distress among medical students are related to academic stress, such as course activities, course load, examinations, teaching and learning hassles, placement hassles, and high workload $(14,16)$. Empirical evidence demonstrates that, psychological distress was positively correlated with burnout (3), which certainly affects performance and mental health (17). Burnout can be conceptualised as a syndrome of emotional exhaustion, depersonalization, and low sense of personal accomplishment (18) that eventually leads to detrimental consequences to mental health and psychological function $(17,19)$. The prevalence of burnout among medical students during medical training is high at approximately $43.3 \%$ (19), in which $35-45 \%$ of medical students had high emotional exhaustion, 26-38\% experienced high depersonalization, and $45-56 \%$ had symptoms suggestive of burnout (17). These facts demonstrate academic stress contribute to psychological distress and burnout, which may contribute to personal and professional consequences, for instance increased rate of medical error, malpractice suits, and increased likelihood of physician suicide (19-21).

Literature shows that medical students with specific personality, especially neuroticism traits, were more vulnerable to developing psychological distress and burnout (19). Neuroticism is generally characterised by a tendency to experience negative feelings and is linked with emotional instability, distress, moodiness, irritability, poor coping ability, and sadness $(22,23)$. Likewise, in the medical context, personality traits are associated with several important areas, which include approach to work, mental health, career success, learning approach, and academic performance of medical students and professionals $(24,25)$. A longitudinal study reported that neuroticism was the strongest factor of psychological distress for medical students during stressful periods, such as the final examination (26). Besides, a study had also shown that burnout was strongly linked to neuroticism and it explained more variance in burnout than work stress (27). These facts suggest individuals with high neuroticism are more vulnerable to developing psychological distress and burnout. The significance of personality traits may have been underestimated in burnout research among medical students, hence this study was an attempt to close this research gap.

Moreover, there is considerable evidence showing that emotional intelligence (EI) is a determinant of success in a variety of occupational settings (28-30). El refers to the ability to perceive, express, understand, motivate, control, and regulate emotion (30-33). A recent systematic review on El in medicine revealed that a higher El positively contributed to important outcomes in the competence of future doctors (29), and El prior to medical training predicted psychological health and academic performance during medical training (26). For example, a cross-sectional study found emotional intelligence negatively correlated with depression and anxiety levels (34), and a longitudinal study found that self-appraisal emotion was the only El dimension related to burnout one year later (35). These facts suggest that El plays a significant role in several areas that are related to psychological health of future doctors.

Considering all facts related to the effects that personality, El, and academic life might have on psychological distress and burnout, this study attempted to provide a best fit structural model for the interrelations of burnout with psychological distress, academic stress, personality, and El. This study 
hypothesized that (a) psychological distress is a predisposing or contributing factor to burnout; (b) academic and psychological stress on the same side or in the same role lead to burnout; and (c) neuroticism and emotional intelligence are predictors or mediators of the link between psychological distress and burnout.

\section{Method}

A cross-sectional study was conducted, and a purposive sampling method was applied with 300 medical students. The acceptable sample size for structural equation modelling is 200 to 300 samples (36). The data collection was carried out immediately after the final preclinical examination. An informed consent was obtained, and participation in this study was on a voluntary basis that would not affect participants' academic progression.

Burnout was measured by the Copenhagen Burnout Inventory (CBI) consists of 19 items. It is the newest and public domain tool developed to assess the core features of burnout (fatigue and exhaustion) in relation to personal life (personal burnout), work (work-related burnout) and service to clients (clientrelated burnout) (37-39). The CBI was validated in the medical student population (40), which has three domains; personal, work-related, and client-related burnout $(38,40)$. The internal structure reliability of the $\mathrm{CBI}$ was good with Cronbach's alpha ranging from 0.83 to 0.87 (40). Reversed scoring was applied in positively worded items, and high scores indicated high levels of burnout.

Psychological distress was measured using the 21-item Depression Anxiety Stress Scale (DASS-21). Researchers have used the DASS-21 to measure symptoms of depression, anxiety, and stress as well as overall psychological distress, in which a high score indicates poor psychological health (41-45). Its validity and reliability among student samples has been well established in previous studies $(42,44,46$, 47). The internal consistency coefficients of depression, anxiety, and stress scales ranged between 0.81 and $0.97(46)$.

El was measured using the 17-item USM Emotional Quotient Inventory (USMEQ-17), which is a valid and reliable tool for measuring El in medical student samples as it demonstrated high internal consistency (Cronbach's alpha was greater than 0.7 ) and good construct validity (48-51). The assessment consists of personal competence and social competence, both domains represented by global El are together the ability to perceive, express, understand, motivate, control, and regulate emotion.

The 15-item USM Personality Traits Inventory (USMaP-15) measures the five-factor personality traits, which are openness, conscientiousness, extroversion, agreeableness, and neuroticism (52-54). It is a valid and reliable tool to measure personality traits in medical student samples as it demonstrated a stable internal consistency (Cronbach's alpha) that ranged from $0.63-0.83$ and a good construct $(52,53$, 55), indicating an acceptable to high level of internal consistency and consistency across time intervals and occasions. 
The 20-item Medical Student Stressors Questionnaire (MSSQ-20) measures the academic stress $(56,57)$. The MSSQ-20 has six domains, including academic, interpersonal, teaching and learning, social, drive/desire, and group activity. It is a self-reported self-scoring instrument that requires medical students to rate the intensity of stress caused by each source. The internal consistency (Cronbach's alpha) for the MSSQ-20 was more than 0.8 and ranged from 0.55 to 0.97 for each MSSQ construct (57). The MSSQ-20 has stable internal consistency over multiple measurements across different time intervals (58).

A descriptive analysis of the demographic data was performed using the Statistical Package for Social Sciences (SPSS) version 20. Structural equation modelling (SEM) was performed to examine the interrelations between observable variables in the proposed model (Fig. 1). CFA and SEM were performed using the Analysis of Moment Structure (AMOS) software. The latent constructs and the proposed model were considered fit if all the goodness of fit indices achieved the minimal requirement (36), as stated in Table 1.

Table 1

Goodness of fit indices used to signify model fitness

\begin{tabular}{|c|c|c|}
\hline Name of category & Name of index & Level of acceptance \\
\hline \multirow[t]{2}{*}{ Absolute fit ${ }^{1}$} & Root mean square of error approximation (RMSEA) & less than 0.08 \\
\hline & Goodness of fit index (GFI) & more than 0.9 \\
\hline \multirow[t]{3}{*}{ Incremental fit ${ }^{2}$} & Comparative fit index (CFI) & more than 0.9 \\
\hline & Tucker-Lewis index (TLI) & more than 0.9 \\
\hline & Normed fit index (NFI) & more than 0.9 \\
\hline Parsimonious $\mathrm{fit}^{3}$ & Chi square/degree of freedom (Chisq/df) & less than 5 \\
\hline \multicolumn{3}{|c|}{$\begin{array}{l}\text { Note. }{ }^{1} \text { Absolute fit: Measures overall goodness of fit for both the structural and measurement models } \\
\text { collectively. This type of measure does not make any comparison to a specified null model } \\
\text { (incremental fit measure) or adjust for the number of parameters in the estimated model } \\
\text { (parsimonious fit measure). }{ }^{2} \text { Incremental fit: Measures goodness of fit that compares the current } \\
\text { model to a specified "null" (independence) model to determine the degree of improvement over the } \\
\text { null model. }{ }^{3} \text { Parsimonious fit: Measures goodness of fit representing the degree of model fit per } \\
\text { estimated coefficient. This measure attempts to correct for any "overfitting" of the model and } \\
\text { evaluates the parsimony of the model compared to the goodness of fit. }\end{array}$} \\
\hline
\end{tabular}

\section{Results}

Out of 300 medical students, 241 students responded completely to the five inventories. The majority of respondents were female $(n=153)$ and non-Malay $(n=122)$, and the mean age was about 21 years $(M=$ 21.8). 
The goodness of fit indices for the psychological distress-burnout relationship and the mediating effects of academic stress, neuroticism, and emotional intelligence are summarised in Table 2. The direct, indirect, and total effects of the model paths are shown in Tables 3 and 4.

Table 2

The goodness of fit indices for supporting the best fit model

\begin{tabular}{|c|c|c|c|c|c|c|c|c|}
\hline \multirow[t]{2}{*}{ Model } & \multirow{2}{*}{$\begin{array}{l}\square^{2} \text { statistics } \\
(d f)\end{array}$} & \multirow{2}{*}{$\begin{array}{l}p- \\
\text { value }\end{array}$} & \multicolumn{6}{|c|}{ Goodness of fit indices } \\
\hline & & & $\square^{2} / d f$ & RMSEA & GFI & $\mathrm{CFI}$ & $\mathrm{NFI}$ & TLI \\
\hline $\begin{array}{l}\text { 1. Model } 1 \\
\text { (Fig. } 1 \text { ) }\end{array}$ & $17.48(8)$ & 0.025 & 2.186 & 0.070 & 0.976 & 0.989 & 0.980 & 0.980 \\
\hline $\begin{array}{l}\text { 2. Model } 2 \\
\text { (Fig. 2) }\end{array}$ & $62.78(29)$ & $<.001$ & 2.165 & 0.070 & 0.951 & 0.973 & 0.952 & 0.958 \\
\hline
\end{tabular}

The psychological distress-burnout relationship achieved model fit (Fig. 1, Table 2: Model 1). The relationship between psychological distress and burnout was significant $(\beta=0.494, B=0.228, S E=0.035$, $p$-value $<0.001)$. When psychological distress went up by 1 unit or standard deviation (SD), burnout went up by 0.228 units or 0.494 SDs. Of importance, psychological distress significantly contributed to the burnout level of medical students.

Table 3

The estimates of standardised and unstandardised regression weights of academic stress, neuroticism, and emotional intelligence on the psychological distress-burnout relationship

\begin{tabular}{|c|c|c|c|c|c|}
\hline Independent variables & Dependent variables & $\beta$ & B & SE & $p$-values \\
\hline Psychological distress & \multirow[t]{3}{*}{ Burnout } & 0.344 & 0.160 & 0.037 & $<0.001$ \\
\hline Emotional intelligence & & -0.176 & -1.376 & 0.483 & 0.004 \\
\hline Academic stress & & 0.168 & 0.781 & 0.309 & 0.012 \\
\hline Academic stress & \multirow[t]{2}{*}{ Psychological distress } & 0.384 & 3.846 & 0.584 & $<0.001$ \\
\hline Neuroticism & & 0.390 & 1.324 & 0.198 & $<0.001$ \\
\hline Neuroticism & Academic stress & 0.202 & 0.068 & 0.021 & 0.001 \\
\hline Psychological distress & \multirow[t]{2}{*}{ Emotional intelligence } & -0.241 & -0.014 & 0.004 & $<0.001$ \\
\hline Neuroticism & & -0.394 & -0.079 & 0.016 & $<0.001$ \\
\hline
\end{tabular}


The psychological distress significantly increased burnout levels and decreased El (Table 3, Fig. 2) When psychological distress increased by 1 unit or SD, burnout increased by 0.160 units or 0.344 SDs. Significantly, the effects of psychological distress on burnout were reduced after including El, academic stress, and neuroticism into the SEM, as compared to Model 1 (Fig. 1). El significantly reduced the burnout level, when El increased, burnout decreased. Furthermore, academic stress significantly increased psychological distress and burnout levels. Thus, when academic stress increased, psychological distress and burnout increased. Additionally, neuroticism significantly increased academic stress and psychological distress, and decreased El. When neuroticism increased, academic stress and psychological distress also increased. 
Table 4

The unstandardised and standardised estimates of direct, indirect, and total effects of academic stress, neuroticism, and emotional intelligence on the psychological distress-burnout relationship

\begin{tabular}{|c|c|c|c|c|c|}
\hline Parameter & $\begin{array}{l}\text { Independent } \\
\text { variable }\end{array}$ & $\begin{array}{l}\text { Dependent } \\
\text { variable }\end{array}$ & $\begin{array}{l}\text { Total } \\
(L, U)\end{array}$ & $\begin{array}{l}\text { Direct } \\
(L, U)\end{array}$ & $\begin{array}{l}\text { Indirect } \\
(\mathrm{L}, \mathrm{U})\end{array}$ \\
\hline \multirow[t]{8}{*}{ Unstandardised } & \multirow{2}{*}{$\begin{array}{l}\text { Psychological } \\
\text { distress }\end{array}$} & \multirow[t]{8}{*}{ Burnout } & 0.179 & 0.160 & 0.020 \\
\hline & & & $\begin{array}{l}(0.099 \\
0.276)^{\star \star \star}\end{array}$ & $\begin{array}{l}(0.073 \\
0.258)^{\star \star \star}\end{array}$ & $\begin{array}{l}(0.003 \\
0.055)^{\star}\end{array}$ \\
\hline & \multirow[t]{2}{*}{ Academic stress } & & 1.470 & 0.781 & 0.689 \\
\hline & & & $\begin{array}{l}(0.838 \\
2.069) \star \star\end{array}$ & $\begin{array}{l}(0.027 \\
1.424)^{\star}\end{array}$ & $\begin{array}{l}(0.373 \\
1.114)^{\star \star *}\end{array}$ \\
\hline & \multirow{2}{*}{$\begin{array}{l}\text { Emotional } \\
\text { intelligence }\end{array}$} & & -1.376 & -1.376 & \multirow[t]{2}{*}{-} \\
\hline & & & $\begin{array}{l}(-2.854 \\
-0.091)^{*}\end{array}$ & $\begin{array}{l}(-2.854 \\
-0.091)^{\star}\end{array}$ & \\
\hline & \multirow[t]{2}{*}{ Neuroticism } & & 0.447 & - & 0.447 \\
\hline & & & $\begin{array}{l}(0.261 \\
0.652)^{\star \star \star}\end{array}$ & & $\begin{array}{l}(0.261 \\
0.652)^{\star \star \star}\end{array}$ \\
\hline \multirow[t]{8}{*}{ Standardised } & \multirow{2}{*}{$\begin{array}{l}\text { Psychological } \\
\text { distress }\end{array}$} & \multirow[t]{8}{*}{ Burnout } & 0.386 & 0.344 & 0.042 \\
\hline & & & $\begin{array}{l}(0.214 \\
0.557)^{\star \star \star}\end{array}$ & $\begin{array}{l}(0.141 \\
0.525)^{\star * *}\end{array}$ & $\begin{array}{l}(0.009 \\
0.113)^{\star}\end{array}$ \\
\hline & \multirow[t]{2}{*}{ Academic stress } & & 0.316 & 0.168 & 0.148 \\
\hline & & & $\begin{array}{l}(0.173 \\
0.429)^{\star \star}\end{array}$ & $\begin{array}{l}(0.006 \\
0.300)^{\star}\end{array}$ & $\begin{array}{l}(0.085 \\
0.231)^{\star \star}\end{array}$ \\
\hline & \multirow{2}{*}{$\begin{array}{l}\text { Emotional } \\
\text { intelligence }\end{array}$} & & -0.176 & -0.176 & \multirow[t]{2}{*}{-} \\
\hline & & & $\begin{array}{l}(-0.376 \\
-0.014)^{\star}\end{array}$ & $\begin{array}{l}(-0.376 \\
-0.014)^{\star}\end{array}$ & \\
\hline & \multirow[t]{2}{*}{ Neuroticism } & & 0.283 & - & 0.283 \\
\hline & & & $\begin{array}{l}(0.184 \\
0.378)^{\star \star}\end{array}$ & & $\begin{array}{l}(0.184 \\
0.378)^{\star \star}\end{array}$ \\
\hline Note. Bootstrap & 000 ) with $95 \%$ bia & orrected co & ce interval & wer boun & upper bour \\
\hline$\star * p$-value $<0.0$ & lue $<0.05$. & & & & \\
\hline
\end{tabular}

The results showed a significant direct effect of psychological distress on burnout (Table 4). However, the effect of psychological distress on burnout was significantly mediated by El (Fig. 2). Additionally, psychological distress significantly decreased El, but El directly decreased burnout levels (Tables 3-4. In other words, emotional intelligence was a protective factor for burnout. 
Additionally, a significant effect was shown with academic stress and neuroticism in the relationship between psychological distress and burnout (Fig. 2; Tables 3-4). Both academic stress and neuroticism increased psychological distress, thereby contributing to the increased burnout level. Academic stress showed both direct and indirect effects on burnout; although, neuroticism only showed an indirect effect on burnout. In other words, academic stress was a predictor of the relationship between psychological distress and burnout; however, neuroticism was a predisposing contributing factor to burnout.

The results also identified that El was significantly reduced by psychological distress and neuroticism, indicating both were negative predictors of El, which suggests that psychological distress and neuroticism increased burnout levels by reducing El levels. These results indicated the significant effects and paths that psychological distress, emotional intelligence, academic stress, and neuroticism have on burnout. Academic stress and neuroticism significantly increase psychological distress, leading to the escalation of burnout levels, while El has a significant effect on reducing burnout; however, this is negatively affected by psychological distress and neuroticism, leading to increased burnout.

\section{Discussion}

This study contributes several important findings to the current body of knowledge. First, psychological distress predominantly has a direct effect on escalating the burnout level of medical students. Second, academic stress has direct and indirect effects (mainly mediated through psychological distress) on increasing the burnout level of medical students during stressful events. Third, neuroticism predominantly has an indirect effect, mediated through psychological distress and academic stress, on increasing medical students' burnout levels during stressful periods. Fourth, El mainly demonstrates a direct effect on reducing the burnout level of medical students during stressful events. Lastly, El was significantly compromised by the increase of psychological distress and neuroticism, leading to burnout.

First, psychological distress predominantly had direct effects on escalating the burnout level of medical students. In fact, it had the greatest direct standardised effect in positively predicting burnout - making it the strongest predictor of burnout in medical students. This finding corresponds to previous studies that showed a significant positive correlation between psychological distress and burnout (3), a significant negative correlation between psychological wellbeing and burnout (59), a significant positive correlation between burnout and depression (60-64), a significant correlation between anxiety and burnout (64-66), and the strong association of burnout severity with the prevalence of depression (67). These indicate that psychological distress is the major predictor of burnout, highlighting the importance of reducing unnecessary psychological pressures (sources of stress that are not needed to be introduced), thus leading to better psychological health and eventually reducing burnout in medical students $(68,69)$. Designing a systematic support system, for instance a peer-support system, to support medical students experiencing difficulty may improve their psychological distress by helping to reduce unnecessary psychological pressures $(12,19)$. 
Second, academic stress demonstrated direct and indirect effects (mainly mediated through psychological distress) on increasing the burnout level of medical students during stressful events. In fact, academic stress had the second greatest total effect on burnout. This finding is consistent with previous studies that reported daily hassles positively correlated with burnout (64), academic stress negatively correlated with personal wellness (70), perceived stress associated with burnout (71), and academic stress as the most predictive of burnout (72). These facts suggest that the psychological wellbeing is negatively affected by high academic stress due to the demands of medical training $(70,73)$. Taib et al. (2020) explained that "Most budding doctors believe that hard work, sweat and dedication would lead to successful careers" (p.66). Unfortunately, many trainees experience medical and mental health problems, which have become more apparent and overwhelming following the demands of clinical training. Thus, empathetic and healing relationships are vital rather than suspicion and hatred when dealing with the unwell student (12). It is possible that lowering superfluous academic stress by reducing unnecessary syllabus, course load, workload, and psychological pressures while fostering psychological support, a healthy learning environment, sufficient learning time, and adequate breaks would improve their psychological wellbeing and prevent them from developing burnout (19).

Third, neuroticism predominantly had an indirect effect (mediated through psychological distress and academic stress) on increasing medical students' burnout levels during stressful periods. Previous studies reported that certain personal traits can contribute to stress among medical students and reduce their wellbeing (73), for instance, neuroticism demonstrated a positive correlation with emotional exhaustion and cynicism and a negative correlation with professional efficacy (74), burnout risk was strongly associated with neuroticism (75); and neuroticism positively correlated with psychological distress (19). These findings recognize neuroticism as a negative predictor of psychological wellbeing. One possible reason is potentially due to the tendency of individuals with high neuroticism to experience negative feelings and to have poor coping ability in stressful circumstances $(77,78)$, making them less suitable for medical training that is complicated and stressful $(79,80)$. On that basis, medical schools should consider including neuroticism as a criterion in the recruitment of candidates into medical programs because it will influence the quality of medical graduates (81).

Fourth, El demonstrated a direct effect on reducing the burnout level of medical students during stressful events. This finding is aligned with several studies reporting that El scores correlate inversely with emotional exhaustion and depersonalization (82), that El was strongly predictive of emotional exhaustion and depersonalization (82), and that higher El scores were significantly correlated with lower burnout (83). These facts indicate that individuals with higher El will have a better psychological state and be less vulnerable to developing burnout. Emotionally intelligent persons know how to handle their own and others' emotions and being able to deal with emotions effectively makes them less vulnerable to developing burnout. Hence, developing a special program to cultivate medical students' El could help students to face the demands and challenges of medical training, thus preventing them from developing burnout. Medical schools could also possibly include El as a criterion for the recruitment of candidates into medical training, thus will minimise the vulnerability of students to develop burnout. 
Lastly, El was significantly compromised by the increase of psychological distress and neuroticism, which led to burnout. It was evident in the literature that El correlated positively with psychological wellbeing and inversely with depression (82), that self-perceived stress was lower in those with higher El (84), that psychological distress showed a negative correlation with El scores (85), and that EI demonstrated negative correlations between anxiety, stress, and depression (86). One important fact from these findings is the indirect mechanism through which psychological distress causes burnout is by lowering the El of medical students. Similarly, personality contributed significantly to El, especially neuroticism, which demonstrated the largest independent negative contribution to the increase of burnout (87) via the same indirect mechanism as psychological distress. This is a significant fact for consideration given that medical students usually have high El but are still vulnerable to burnout if they are consistently exposed to chronic excessive psychological pressure. This is known as a wear and tear phenomenon due to the depletion of the emotional reservoir in handling chronic exposure to prolonged excessive psychological pressures (88), especially in those with high neuroticism.

Based on the SEM, several practical applications can be recommended to medical educators, students, and medical schools. First, medical educators should try their best to avoid introducing psychological pressures that are not needed to students, especially academic-related stress. This approach will minimise the sources of psychological distress and burnout, hence, lead to better mental health. Second, medical students should do their best to develop a positive and healthy mindset towards academic matters that will help them to thrive under pressure. Third, medical schools should introduce programs that help medical students manage their stress and develop their El. These wellbeing strategies will foster resilience and prevent burnout. Lastly, medical schools maybe should consider including neuroticism and El as part of the admission criteria to recruit candidates into the medical program. Candidates with low neuroticism and high El will be able to handle the medical training pressure in a better way, thus minimising the probability of them developing psychological distress and burnout.

It is worthy to mention this research was conducted at a medical school; therefore, any attempt to generalise the results to other settings should be done cautiously. A multi-centre research should be conducted in the future to validate the proposed model. Besides, the sampling technique used was not the ideal method due to the limitation of the non-probability technique due to sampling bias, which may cause imprecision of the obtained results. Hence, future research should use the probability sampling technique to overcome this limitation. Despite these limitations, this research has several strengths. First, the research variables were measured by validated research tools, and the obtained results supported the measurement model fit. Second, the sample size was satisfactory for SEM; thus, the obtained results are trustworthy for the proposed structural model. Third, the analysis was conducted by standard and recommended statistical software; therefore, the obtained results can be trusted and compared with previous studies. Lastly, as far as the author is aware, this is the first attempt to describe the causal-effect relationships of burnout, psychological distress, academic stress, neuroticism, and El through SEM.

\section{Conclusion}


The results revealed significant effects and paths that psychological distress, El, academic stress, and neuroticism have on burnout. Academic stress and neuroticism significantly increased psychological distress, leading to increased burnout levels, while El had a significantly direct effect on reducing burnout; however, this was compromised by psychological distress and neuroticism leading to increased burnout. This study explained the causal-effect relationships of burnout, psychological distress, academic stress, neuroticism, and El through SEM.

\section{Declarations}

\section{Acknowledgements}

Our deepest gratitude is given to all the respondents for their time, cooperation, and patience in completing the questionnaires administered to them.

\section{Funding}

This study has no funding to be declared

\section{Conflicts of interest}

No conflict of interest to be declared

\section{Ethics approval and consent to participate}

This study was approved by the Human Research Ethics Committee of Universiti Sains Malaysia (Reference Code:USMKK/PPP/JEPeM(212.4[2.5]). Informed consent was obtained from each participant prior to the study. All methods were carried out in accordance with relevant guidelines and regulations.

\section{Consent for publication}

Participants had given consent to publish the data as long as the anonymity is maintained.

\section{Availability of data and material}

The datasets used and/or analysed during the current study are available from the corresponding author on reasonable request.

\section{Code availability}

Not applicable

\section{Authors' contributions}

Yusoff MSB. Substantial contributions to the conception of the work, the acquisition and analysis of data, drafting the work, final approval of the version to be published, and agreement to be accountable for 
all aspects of the work. Hadie SNH. Substantial contributions to the design of the work, the analysis and interpretation of data, revising it critically for important intellectual content, final approval of the version to be published, and agreement to be accountable for all aspects of the work. Mohd Yasin MA:

Substantial contributions to the interpretation of data, drafting the work, final approval of the version to be published, and agreement to be accountable for all aspects of the work.

\section{References}

1. Ridner SH. Psychological distress: Concept analysis. Journal of Advanced Nursing. 2004.

2. Shih $M$, Simon PA. Health-related quality of life among adults with serious psychological distress and chronic medical conditions. Qual Life Res. 2008;

3. Zou G, Shen X, Tian X, Liu C, Li G, Kong L, et al. Correlates of psychological distress, burnout, and resilience among Chinese female nurses. Ind Health [Internet]. 2016 [cited 2020 Apr 10];54(5):38995. Available from: https://www.jstage.jst.go.jp/article/indhealth/54/5/54_2015-0103/_article

4. Dyrbye LN, Thomas MR, Shanafelt TD. Medical student distress: causes, consequences, and proposed solutions. Mayo Clin. 2005;

5. Yusoff MSB, Abdul Rahim AF, Baba AA, Ismail SB, Mat Pa MN, Esa AR. Prevalence and associated factors of stress, anxiety and depression among prospective medical students. Asian J Psychiatr [Internet]. 2013;6(2):128-33. Available from: http://dx.doi.org/10.1016/j.ajp.2012.09.012

6. Smith CK, Peterson DF, Degenhardt BF, Johnson JC. Depression, anxiety, and perceived hassles among entering medical students. Psychol Health Med [Internet]. 2007;12(1):31-9. Available from: http://dx.doi.org/10.1080/13548500500429387

7. Yusoff M, Abdul Rahim A, Baba A, Ismail S, Mat Pa M, Esa A. The impact of medical education on psychological health of students: a cohort study. Psychol Health Med [Internet]. 2013;18(4):420-30. Available from: http://www.ncbi.nlm.nih.gov/pubmed/23140393

8. Yusoff MSB, Mat Pa MN, Esa AR, Abdul Rahim AF. Mental health of medical students before and during medical education: A prospective study. J Taibah Univ Med Sci [Internet]. 2013;8(2):86-92. Available from: http://www.sciencedirect.com/science/article/pii/S1658361213000346

9. Elias H, Ping WS, Abdullah MC. Stress and academic achievement among undergraduate students in Universiti Putra Malaysia. In: Procedia - Social and Behavioral Sciences. 2011.

10. Yusoff MSB, Arifin WN. Educational environment and psychological distress of medical students: The role of a deep learning approach. J Taibah Univ Med Sci. 2015;10(4).

11. World Health Organization. Investing in Mental Health. Geneva: World Health Organization; 2003. 4 p.

12. Taib F, Van Rostenberghe H, Othman A. "Sorry You Are Not Fit to be a Doctor": Do We Need to Penalise Unwell Medical Trainees? Educ Med J. 2020;12(1):65-9.

13. Yen Yee L, Yusoff MSB. Prevalence and sources of stress among medical students in Universiti Sains Malaysia and Universiteit Maastricht. Educ Med J. 2013; 
14. Yusoff MSB, Abdul Rahim AF, Yaacob MJ. Prevalence and sources of stress among Universiti Sains Malaysia medical students. Malaysian J Med Sci. 2010;17(1).

15. Yusoff MSB, Liew YY, Ling HW, Loke HM, Lim X Bin, Chin SC, et al. A study on stress, stressors and coping strategies among Malaysian medical students. Int J Students' Res. 2011;1(2):45-50.

16. Yusoff MSB, Hamid AHA, Rosli NR, Zakaria NA, Rameli NAC, Rahman NSA, et al. Prevalence of stress, stressors and coping strategies among secondary school students in Kota Bharu, Kelantan, Malaysia. Int J Student Res. 2011;1(1):23-8.

17. Dyrbye L, Shanafelt T. A narrative review on burnout experienced by medical students and residents. Med Educ. 2016;

18. Maslach C, Jackson S, Leiter M. Maslach Burnout Inventory Manual. 3rd ed. Palo Alto, CA: Consulting Psychologist Press; 1996.

19. Yusoff MSB. Promoting resilience and minimizing burnout. In: MA H, CU K, R D, F M, R B, AG H, editors. Wellbeing in higher education: cultivating a healthy lifestyle among faculty and students. New York: Routledge; 2018. p. 82-105.

20. Dyrbye LN, Thomas MR, Massie FS, Power D V., Eacker A, Harper W, et al. Burnout and suicidal ideation among U.S. medical students. Ann Intern Med. 2008;

21. Felaza E, Findyartini A, Setyorini D, Mustika R. How Motivation Correlates with Academic Burnout: Study Conducted in Undergraduate Medical Students. Educ Med J. 2020;12(1):43-52.

22. Goldberg LR. A broad-bandwidth, public domain, personality inventory measuring the lower-level facets of several five-factor models. In: Mervielde I, Deary I, De Fruyt F, Osterdorf F, editors. Personality Psychology in Europe. Tilburg, Netherland: Tilburg University Press; 1999. p. 7-28.

23. Goldberg LR, Johnson JA, Eber HW, Hogan R, Ashton MC, Cloninger CR, et al. The international personality item pool and the future of public-domain personality measures. J Res Pers. 2006;

24. McManus IC, Keeling A, Paice E. Stress, burnout and doctors' attitudes to work are determined by personality and learning style: A twelve year longitudinal study of UK medical undergraduates. BMC Med. 2004;2(9).

25. Trapmann S, Hell B, Hirn JOW, Schuler H. Meta-analysis of the relationship between the Big Five and academic success at university. Journal of Psychology. 2007.

26. Yusoff MS, Esa AR, Mat Pa MN, Mey SC, Aziz RA, AF AR. A longitudinal study of relationships between previous academic achievement, emotional intelligence and personality traits with psychological health of medical students during stressful periods. Educ Heal. 2013;26(1):39.

27. Bianchi R. Burnout is more strongly linked to neuroticism than to work-contextualized factors. Psychiatry Res. 2018;

28. Ann G. Emotional Intelligence, the Witness and Education. Educ Mean Soc Justice. 2002;15(4):21-9.

29. Arora S, Ashrafian H, Davis R, Athanasiou T, Darzi A, Sevdalis N. Emotional intelligence in medicine: a systematic through the context of the ACGME competencies. Med Educ. 2010;44(749-764). 
30. Mayer JD, Roberts RD, Barsade SG. Human abilities: Emotional Intelligence. Annu Rev Psychol. 2008;59:507-36.

31. Goleman D. Emotional Intelligence. New York: Bantam; 1995.

32. Goleman D. Working with emotional intelligence. Bantam; 1998.

33. Mayer JD, Salovey P. The intelligence of emotional intelligence. Intelligence. 1993.

34. Skokou M, Sakellaropoulos G, Zairi NA, Gourzis P, Andreopoulou O. An Exploratory Study of Trait Emotional Intelligence and Mental Health in Freshmen Greek Medical Students. Curr Psychol. 2019;

35. Carvalho VS, Guerrero E, Chambel MJ. Emotional intelligence and health students' well-being: A twowave study with students of medicine, physiotherapy and nursing. Nurse Educ Today. 2018;

36. Schreiber JB, Stage FK, King J, Nora A, Barlow EA. Reporting structural equation modeling and confirmatory factor analysis results: A review. Journal of Educational Research. 2006.

37. Shirom A. Reflections on the study of burnout. Work and Stress. 2005.

38. Kristensen TS, Borritz M, Villadsen E, Christensen KB. The Copenhagen Burnout Inventory: A new tool for the assessment of burnout. Work Stress. 2005;19(3):192-207.

39. Schaufeli WB, Leiter MP, Maslach C. Burnout: 35 years of research and practice. Career Development International. 2009.

40. Chin RWA, Chua YY, Chu MN, Mahadi NF, Wong MS, Yusoff MSB, et al. Investigating validity evidence of the Malay translation of the Copenhagen Burnout Inventory. J Taibah Univ Med Sci. 2018;13(1):19.

41. Alfonsson S, Wallin E, Maathz P. Factor structure and validity of the Depression, Anxiety and Stress Scale-21 in Swedish translation. J Psychiatr Ment Health Nurs. 2017;

42. Crawford JR, Henry JD. The Depression Anxiety Stress Scales (DASS): Normative data and latent structure in a large non-clinical sample. Br J Psychol Soc. 2003;42:111-31.

43. Henry JD, Crawford JR. The short-form version of the Depression Anxiety Stress Scales (DASS-21): Construct validity and normative data in a large non-clinical sample. Br J Clin Psychol. 2005;44:22739.

44. Lovibond SH, Lovibond PF. Manual for the Depression Anxiety Stress Scales. 2nd ed. Sydney: Pscyhology Foundation; 1995.

45. Yusoff MSB. Psychometric properties of the depression anxiety stress scale in a sample of medical degree applicants. Int Med J. 2013;20(3).

46. McDowell I. Measuring health: A guide to rating scales and questionnaires. 3rd ed. New York: Oxford University Press; 2006.

47. Yusoff MSB. Psychometric properties of the Depression Anxiety Stress Scale in a sample of medical degree applicants. Int Med J [Internet]. 2013;20(3):295-300. Available from: http://ovidsp.ovid.com/ovidweb.cgi?T=JS\&PAGE=reference\&D=psyc10\&NEWS=N\&AN=2013-29693003 
48. Arifin WN, Yusoff MSB. Confirmatory Factor Analysis of the Universiti Sains Malaysia Emotional Quotient Inventory Among Medical Students in Malaysia. SAGE Open. 2016;6(2).

49. Arifin WN, Yusoff MSB, Naing NN. Confirmatory factor analysis (CFA) of USM Emotional Quotient Inventory (USMEQ- i) among medical degree program applicants in Universiti Sains Malaysia (USM). Educ Med J. 2012;4(2):e26-44.

50. Yusoff MSB. Stability of USMEQ-i in measuring emotional intelligence in medical students. ASEAN J Psychiatry. 2012;13(1).

51. Yusoff MSB, Rahim AFA, Mat Pa MN, See CM, Ja'afar R, Esa AR. The validity and reliability of the USM Emotional Quotient Inventory (USMEQ-i): Its use to measure emotional quotient (EQ) of future medical students. Int Med J. 2011;18(4):293-9.

52. Yusoff MSB. Construct validity, internal consistency and normative data of the USMaP-i in a sample of medical students. Int Med J. 2013;20(1).

53. Yusoff MSB, Rahim AFA, Abd Aziz R, Mat Pa MN, See CM, Ja'afar R, et al. The validity and reliability of the USM Personality Inventory (USMaP-i): Its use to identify personality of future medical students. Int Med J. 2011;18(4):283-7.

54. Yusoff MSB. Stability of the USMaP-i in measuring the big five personality traits. Int Med J [Internet]. 2013;20(1):69-71. Available from: http://www.scopus.com/inward/record.url?eid=2-s2.084875472423\&partnerID=tZOtx3y1

55. Nur Farliza S, Wan Nor A, Yusoff MSB, Yaacob NA, Nyi Nyi N. A Confirmatory Factor Analysis of USM Personality Inventory (USMaP-i) among Medical Degree Program Applicants in Universiti Sains Malaysia. Educ Med J. 2016;8(1):55-65.

56. Yusoff MSB. A Confirmatory Factor Analysis Study on the Medical Student Stressor Questionnaire among Malaysian Medical Students. Educ Med J. 2011;3(1):44-53.

57. Yusoff MSB. A systematic review on validity evidence of medical student stressor questionnaire. Educ Med J. 2017;9(1).

58. Yusoff MSB. The stability of MSSQ to measure stressors among medical students. Int Med J. 2013;20(2).

59. Yu J, Chae S. The mediating effect of resilience on the relationship between the academic burnout and psychological well-being of medical students. Korean J Med Educ. 2020;

60. Puranitee P, Saetang S, Sumrithe S, Busari JO, van Mook WNKA, Heeneman S. Exploring burnout and depression of Thai medical students: the psychometric properties of the Maslach burnout inventory. Int J Med Educ [Internet]. 2019 [cited 2020 Apr 10];10:223-9. Available from: https://www.researchgate.net/publication/337673358

61. Leiter MP, Durup J. The discriminant validity of burnout and depression: A confirmatory factor analytic study. Anxiety, Stress Coping. 1994;

62. Raedeke TD, Arce C, De Francisco C, Seoane G, Ferraces MJ. The construct validity of the spanish version of the $A B Q$ using a multi-trait/multi-method approach. An Psicol. 2013; 
63. Hakanen JJ, Schaufeli WB. Do burnout and work engagement predict depressive symptoms and life satisfaction? A three-wave seven-year prospective study. J Affect Disord. 2012;

64. Shankland R, Kotsou I, Vallet F, Bouteyre E, Dantzer C, Leys C. Burnout in university students: the mediating role of sense of coherence on the relationship between daily hassles and burnout. High Educ. 2019;

65. Roy A, Druker S, Hoge EA, Brewer JA. Physician anxiety and burnout. Symptom correlates and a prospective pilot study of app-delivered mindfulness training (Preprint). JMIR mHealth uHealth [Internet]. 2019 Apr 1 [cited 2020 Apr 10];8(4):e15608. Available from:

http://www.ncbi.nlm.nih.gov/pubmed/32234708

66. Burr J, Beck Dallaghan GL. The Relationship of Emotions and Burnout to Medical Students' Academic Performance. Teach Learn Med. 2019;

67. Fitzpatrick O, Biesma R, Conroy RM, McGarvey A. Prevalence and relationship between burnout and depression in our future doctors: A cross-sectional study in a cohort of preclinical and clinical medical students in Ireland. BMJ Open. 2019;

68. Witt K, Boland A, Lamblin M, McGorry PD, Robinson J, Veness B, et al. Effectiveness of universal programmes for the prevention of suicidal ideation, behaviour and mental ill health in medical students: a systematic review and meta-analysis. Evid Based Ment Health. 2019;

69. Yusoff MSB. Interventions on medical students' psychological health: A meta-analysis. J Taibah Univ Med Sci [Internet]. 2014;9(1):1-13. Available from: http://dx.doi.org/10.1016/j.jtumed.2013.09.010

70. Yousaf T, Kawal Z, Zainab B, Nawaz H, Ahsan A, Shaheen L. Relationship between Academic Stress and Personal Wellness among Medical University Students. Liaquat Med Res J. 2017;1(3):70-3.

71. Vidhukumar K, Hamza M. Prevalence and correlates of burnout among undergraduate medical students-A cross-sectional survey. Indian J Psychol Med [Internet]. 2020 Mar 1 [cited 2020 Apr 11];42(2):122-7. Available from: http://www.ijpm.info/text.asp?2020/42/2/122/273394

72. Hish AJ, Nagy GA, Fang CM, Kelley L, Nicchitta C V., Dzirasa K, et al. Applying the stress process model to stress-burnout and stress-depression relationships in biomedical doctoral students: $A$ cross-sectional pilot study. CBE Life Sci Educ. 2019;18(Winter):1-11.

73. Bergmann C, Muth T, Loerbroks A. Medical students' perceptions of stress due to academic studies and its interrelationships with other domains of life: a qualitative study. Med Educ Online [Internet]. 2019 [cited 2020 Apr 11];24(1):1-10. Available from: https://www.tandfonline.com/action/journallnformation?journalCode=zmeo20

74. Morgan B, De Bruin K. The relationship between the big five personality traits and burnout in South African university students. South African J Psychol. 2010;40(2):182-91.

75. Prins DJ, van Vendeloo SN, Brand PLP, Van der Velpen I, de Jong K, van den Heijkant F, et al. The relationship between burnout, personality traits, and medical specialty. A national study among Dutch residents. Med Teach. 2019; 
76. Yusoff M. Which Personality Traits Have Favourable Impact on Psychological Health During Stressful Condition? Educ Med J. 2018;10(1):35-42.

77. Oishi S, Schimmack U. Residential Mobility, Well-Being, and Mortality. J Pers Soc Psychol. 2010;

78. Rothmann S, Coetzer EP. The big five personality dimensions and job performance. SA J Ind Psychol. 2003;

79. Spector PE, Jex SM, Chen PY. Relations of incumbent affect-related personality traits with incumbent and objective measures of characteristics of jobs. J Organ Behav. 1995;

80. Seibert SE, Kraimer ML. The Five-Factor Model of Personality and Career Success. J Vocat Behav. 2001;

81. Downie RS, Charlton B. The Making of a Doctor: Medical Education in Theory and Practice. BMJ. 1993;306(5):1352.

82. Lin DT, Liebert CA, Tran J, Lau JN, Salles A. Emotional Intelligence as a Predictor of Resident WellBeing. In: Journal of the American College of Surgeons. Elsevier Inc.; 2016. p. 352-8.

83. Holliday EB, Bonner JA, Formenti SC, Hahn SM, Kalnicki S, Liu FF, et al. Emotional Intelligence and Burnout in Academic Radiation Oncology Chairs. J Healthc Manag. 2017;

84. Ranasinghe P, Wathurapatha WS, Mathangasinghe Y, Ponnamperuma G. Emotional intelligence, perceived stress and academic performance of Sri Lankan medical undergraduates. BMC Med Educ. 2017;

85. Mahaur R, Jain P, Jain AK. Mental Health \& Emotional Intelligence 383 Original Article Association of Mental health. Vol. 61, Indian J Physiol Pharmacol. 2017.

86. Kousha $M$, Bagheri $H$, Heydarzadeh $A$. Emotional intelligence and anxiety, stress, and depression in Iranian resident physicians. J Fam Med Prim Care. 2018;7(2):420.

87. Abe K, Niwa M, Fujisaki K, Suzuki Y. Associations between emotional intelligence, empathy and personality in Japanese medical students. BMC Med Educ. 2018;

88. Dunn LB, Iglewicz A, Moutier C. A conceptual model of medical student well-being: Promoting resilience and preventing burnout. Academic Psychiatry. 2008.

\section{Figures}




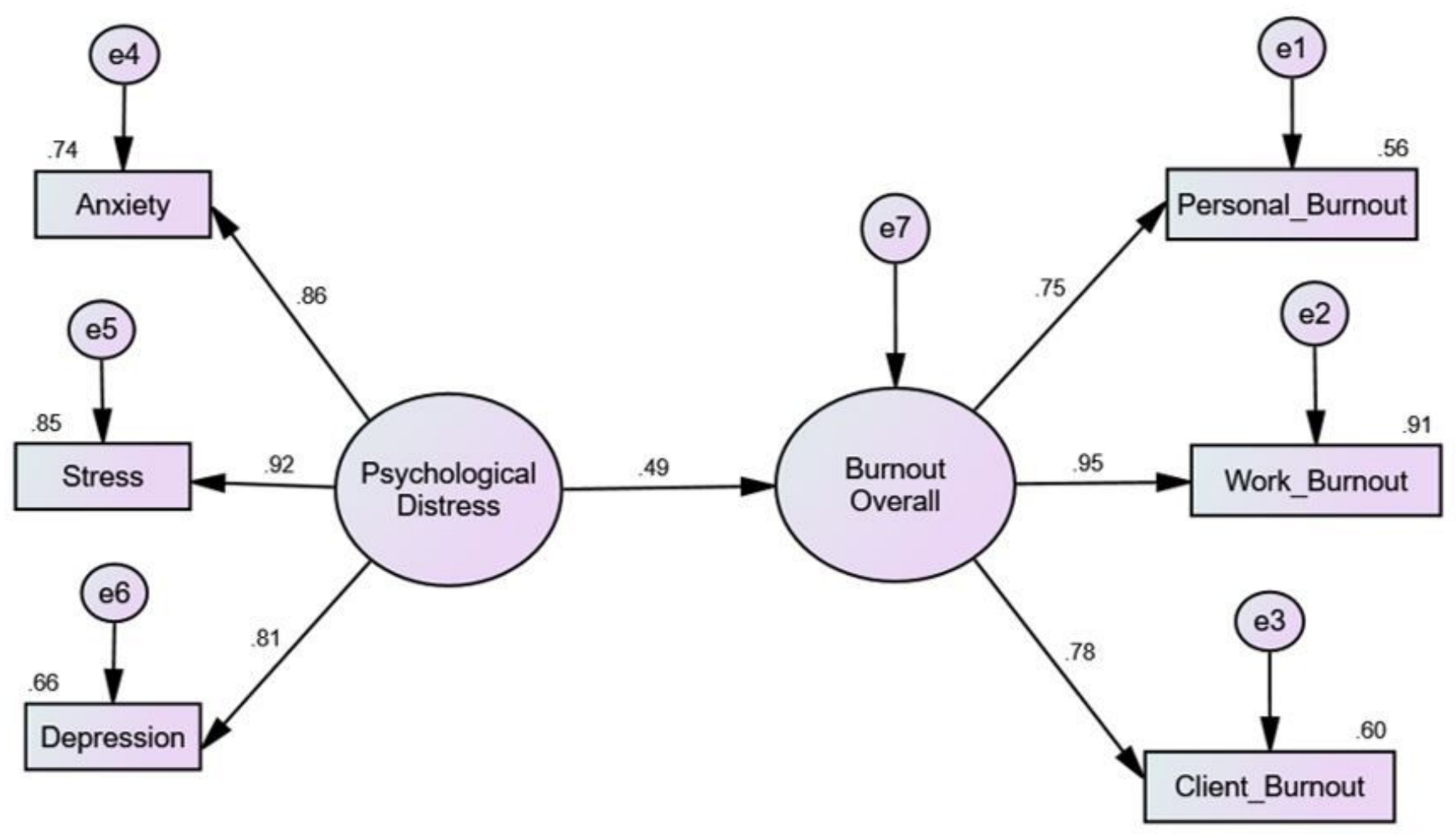

\section{Figure 1}

Structural equation modelling (standardised estimates) of the psychological distress-burnout relationship.

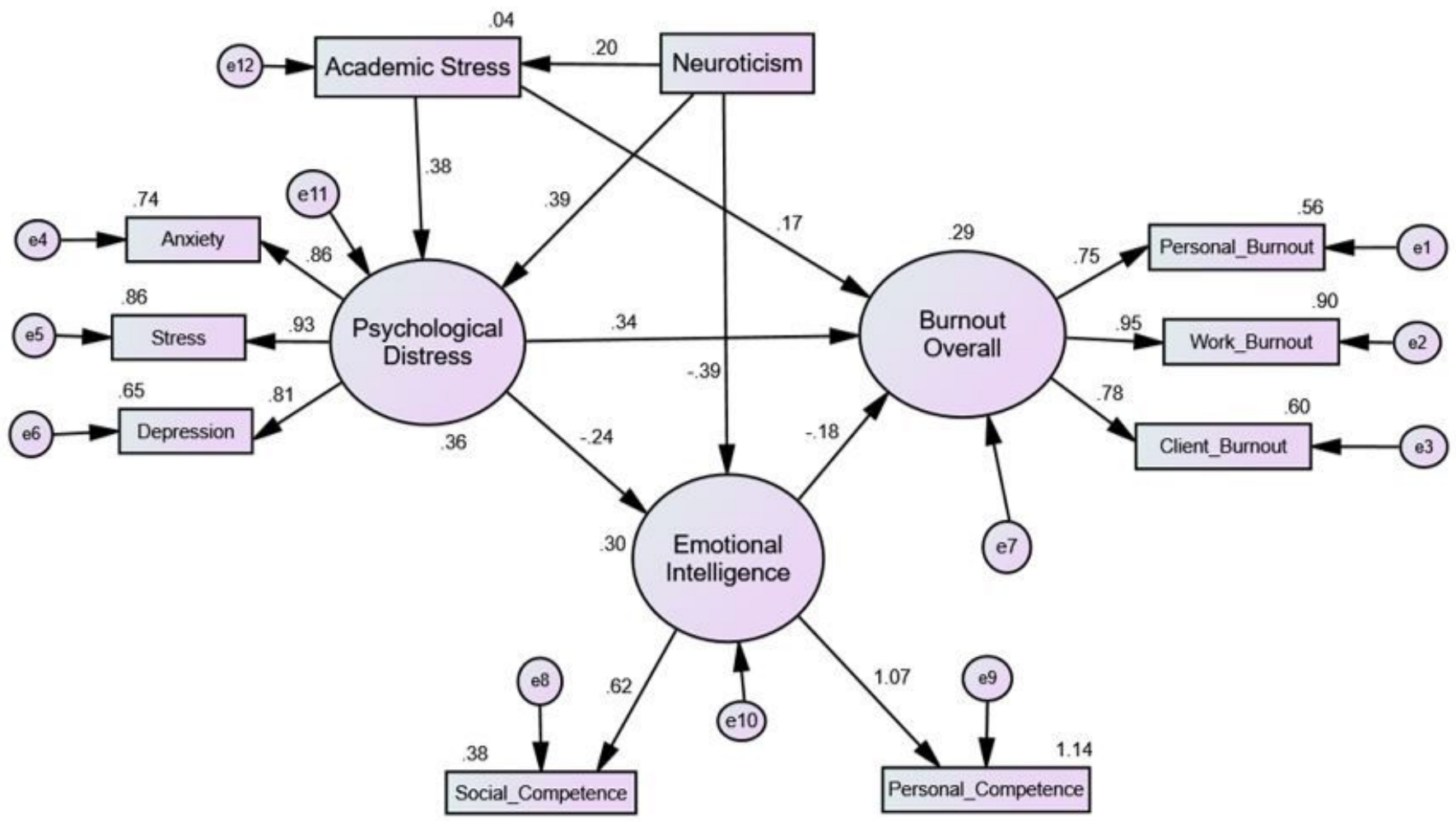


Figure 2

Structural equation modelling (standardised estimates) for the mediating effects of academic stress, neuroticism, and emotional intelligence on the psychological distress-burnout relationship. 